\title{
MODELING AND FORECASTING THE HOUSEHOLD WATER CONSUMPTION IN SAUDI ARABIA
}

\author{
AlmANJAHIE, IBRAHIM M. - ChIKR-ElmeZOUAR, Z. ${ }^{*}$ BACHIR, A. \\ Department of Mathematics, College of Science, King Khalid University \\ 61413 Abha, Saudi Arabia \\ (phone: +966-17-241-7734; fax: +966-17-241-7637) \\ *Corresponding author \\ e-mail: chikrtime@yahoo.fr \\ (Received $1^{\text {st }}$ Oct 2017; accepted $2^{\text {nd }}$ Jan 2019)
}

\begin{abstract}
The demand for water in the kingdom of Saudi Arabia increases due to population growth urbanization, industrialization and the expansion of irrigated agricultural lands. Analyzing the current situation of the water consumption and predicting water demand in the future are essential for the authorities to improve and manage production quantities. The objective of this paper is to find the best model for water consumption in Saudi Arabia and use the fitted model for forecasting. A data for water consumption between January 2010 and July 2017 were analyzed using a multiplicative seasonal autoregressive integrated moving average model (SARIMA). Through our research, we concluded that the best SARIMA model for fitting water consumption in Saudi Arabia is SARIMA $(1,0,1) \times(1,1,2) 12$.
\end{abstract}

Keywords: water consumption, time series, SARIMA, ACF, PACF, Box-Jenkins

\section{Introduction}

It is widely recognized that the kingdom of Saudi Arabia is one of many countries of the world are entering an era of severe water shortage. Saudi Arabia, with an area of 2.15 million $\mathrm{km}^{2}$, is a desert-like country lying in the Middle East in a zone where temperatures are very high in summer and low in winter. The country receives very little of precipitation throughout the year and also does not contain perennial rivers or stable bodies of water. The desert lands throughout the country frequently lose more moisture through evaporation than they receive from precipitation. In fact, more than half of the area of Saudi Arabia is desert. Recently, the arid and water deficit threaten the stability of the country.

The causes of water scarcity are varied; some are natural and others are as a result of human activities. Population growth and the climatic conditions pose a continual challenge and cause the limitation of underground water resources. Also, urbanization, industrialization and the expansion of irrigated agricultural lands have contributed to a dramatic increase in water consumption over the past few decades. Many researchers have discussed the influence of the depletion of underground water resources. They were interested in studying, analyzing and predicting the future demand for water. The journals "Land Economics" and "Water Resources Research" have dedicated much space to this study. Water consumption and demand estimation in developed countries have been at the core of many empirical papers, starting with the work of Gottlieb (1963) and Howe and Lina weaver (1967). Many studies have been made in a large set of countries including Canada (Kulshreshtha, 1996), Denmark (Hansen, 1996), France (Nauges and Thomas, 2000), Spain (Martínez-Espiñeira, 2002), Sweden (Höglund, 1999), and the US (Foster and Beattie, 1979; Agthe and Billings, 1980; Chicoine et al., 
1986; Nieswiadomy and Molina, 1989). Comprehensive reviews of the literature can be found, for examples, in Arbués-Gracia et al. (2003) and Dalhuisen et al. (2003).

Statistical methodologies have been used by many researchers as a tool for understanding and predicting future water demand. Kambale et al. (2016) used autoregressive integrated moving average (ARIMA) model for predicting the climate change scenarios by Inter-Governmental Panel for Climate Change (IPCC) and Indian Network for Climate Change Assessment (INCCA). Hongyan et al. (2017) combined ARIMA model and neural network to propose a prediction model. They used it to predict the 15 years supply and demand for water resources in Shandong Province. Generally, there are many studies dealt with different types of statistical models. We cite, for instance, Cornillon et al. (2008) for principal component analysis (PCA); Rita et al. (2013) and Samsuri et al. (2017) for multiple linear regression model.

In the Kingdom of Saudi Arabia, a general study for the most concise summary of groundwater resources was presented by Al-Ibrahim (1990). He stated that groundwater is the most important source of water in Saudi Arabia. Later, Abushammala and Bawazir (2017) developed an artificial neural network (ANN) model and used it to predict the annual and monthly domestic water demand in Makkah city, Saudi Arabia. Recently, Muhamed et al. (2018) proposed a hybrid model of ANN and ARIMA for predicting the water quality data. They found that the proposed hybrid model is better than the traditional methods and ANN.

None of the previous studies used and discussed the seasonal autoregressive integrated moving average (SARIMA) for predicting water demand in Saudi Arabia. In this paper, we aim to understand the current household water consumption and build a model that will encourage sustainable consumption and conservation of water resources.

A monthly data for the household water consumption in Saudi Arabia will be analyzed and modeled using the SARIMA model. There are two types of this model; additive and multiplicative. For monthly data, an additive model assumes that the difference in the water consumption values between the beginning and middle of each year is approximately the same. For a multiplicative model, the absolute differences in the consumption values are of less interest and importance than the percentage changes. We use the multiplicative SARIMA model since the pattern of the seasonal factor varies with the time series. The monthly water demand model, based on the SARIMA model, is essential for public authorities to improve monthly water production quantities. This study will be utilized for future development programs consideration; especially capital expenditures and water quantities.

The paper is structured as follows: In "Materials and methods" the household water consumption data used in this research is described and the notation of the multiplicative SARIMA model is established. Some models for the data are built and discussed in "Results and discussion". Also, the best SARIMA model is stated. Finally, "Conclusion" is devoted to the conclusion and recommendation.

\section{Materials and methods}

\section{Data collection}

Data, for the household water consumption, between January 2010 and July 2017 were obtained from the Ministry of Environment, Water and Agriculture in Saudi Arabia. The data was monthly for the household water consumption, and it is measured in cubic meters $\left(\mathrm{m}^{3}\right)$ as the water follows through the water meter. The lowest total 
water consumption was in February 2010 with $161 \times 10^{6} \mathrm{~m}^{3}$ while the highest was in May 2017 with $285 \times 10^{6} \mathrm{~m}^{3}$. The data values are displayed in the Appendix.

\section{Multiplicative seasonal ARIMA model}

The dependence on groundwater supplies often emerges in importance during seasonal lags. Natural phenomena such as temperature also have strong components corresponding to seasons. Because of this, it is appropriate to introduce autoregressive and moving average polynomials that identify with the seasonal lags.

The seasonal autoregressive moving average model, say, ARMA (p, q), takes the form $(E q .1)$

$$
\Phi_{\mathrm{p}}\left(B^{g}\right) x_{\mathrm{t}}=\theta_{Q}\left(B^{g}\right) \omega_{\mathrm{t}},
$$

with the following definition. The operators (Eq. 2)

$$
\Phi_{\mathrm{p}}\left(B^{S}\right) x_{\mathrm{t}}=1-\Phi_{1} B^{S}-\Phi_{2} B^{2 S}-\cdots-\Phi_{p} B^{P S}
$$

and $(E q .3)$

$$
\theta_{Q}\left(B^{S}\right)=1+\theta_{1} B^{S}+\theta_{2} B^{2 S}+\cdots+\theta_{Q} B^{Q S},
$$

are the seasonal autoregressive operator and the seasonal moving average operator of orders $\mathrm{P}$ and $\mathrm{Q}$, respectively, with seasonal period S.

The multiplicative seasonal autoregressive integrated moving average (SARIMA) model of Box Jenkins (Box and Jenkins, 1970) is given by Equation 4:

$$
\Phi_{p}\left(B^{S}\right) \varphi(B) \nabla_{s}^{D} \nabla^{d} x_{t}=\theta_{Q}\left(B^{S}\right) \theta(B) \omega_{t},
$$

where $\omega_{t}$ is the usual Gaussian white noise process. The one shorthand notation for the model is

$$
\operatorname{ARIMA}(\mathrm{p}, \mathrm{d}, \mathrm{q}) \times(\mathrm{P}, \mathrm{D}, \mathrm{Q}) \mathrm{S}
$$

With $p=$ non-seasonal AR order, $d=$ non-seasonal differencing, $q=$ non-seasonal MA order, $P=$ seasonal AR order, $D=$ seasonal differencing, $Q=$ seasonal MA order, and $S=$ time span of repeating seasonal pattern. The non-seasonal difference components are $\nabla^{d}=(1-B)^{d}$ and the seasonal is $\nabla_{S}^{D}=\left(1-B^{S}\right)^{D}$ (Davis, 2005; Dickey

\begin{tabular}{|c|c|c|c|}
\hline & $\mathbf{A R}(\mathbf{P})_{\mathrm{S}}$ & $\mathbf{M A}(\mathbf{Q})_{\mathbf{S}}$ & ARMA $(\mathbf{P}, \mathbf{Q})_{\mathrm{S}}$ \\
\hline $\mathrm{ACF}$ & Tails off at lags ks, $\mathrm{k}=1,2, \ldots$ & Cuts off after lag Qs & Tails off at lag ks \\
\hline PACF & Cuts off after lag Ps & Tails off at lags $\mathrm{ks} k=1,2 \ldots$ & Tails off at lag ks \\
\hline
\end{tabular}
et al., 1979). Identification of $\mathrm{AR}(\mathrm{p}) \mathrm{s}, \mathrm{MA}(\mathrm{Q}) \mathrm{s}$ and then an ARMA model is often best done with the ACF and PACF. Table 1 gives a guideline for choosing the best model.

Table 1. Behavior of the ACF and the PACF for the Seasonal ARMA model (Chicoine et al., 1986) 


\section{Results and discussion}

\section{Data exploration}

The plot of the household water consumption series is given in Figure 1.

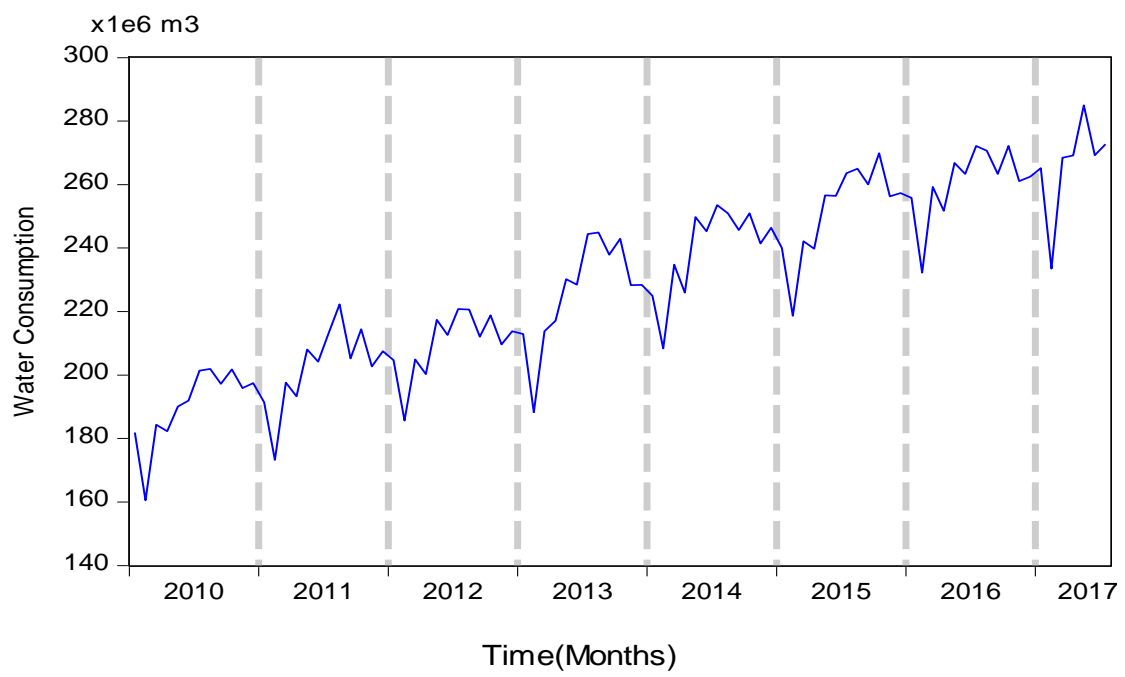

Figure 1. Monthly water consumption in Saudi Arabia between January 2010 and July 2017

From Figure 1 we can see that there are clear patterns of seasonality. The seasonal variation increases as we move across time. Also, there is a clearly increasing trend in water consumption over time.

\section{Building SARIMA model}

To build a multiplicative seasonal autoregressive integrated moving average (SARIMA) model based on the Box Jenkins method (Box and Jenkins, 1970), the stages of this method for analyzing time series data are followed: identification, estimation, diagnostic checking and forecasting. For identification, the autocorrelation function $(\mathrm{ACF})$ and partial autocorrelation function (PACF) are used for checking stationarity of the data series and determining if possible the values of p, P, q, Q. Figures 2 and 3 display the results of ACF and PACF.

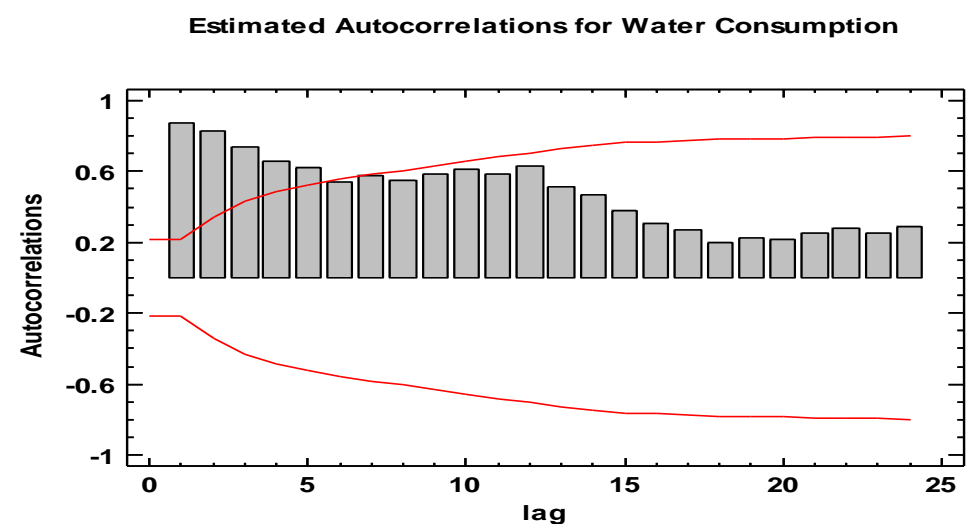

Figure 2. The ACF for the monthly water consumption data in Saudi Arabia between January 2010 and October 2016 
The autocorrelations of the water consumption are significant for a large number of seasonal lags, but perhaps the autocorrelations at lags 12 and above are merely due to the propagation of the autocorrelation at lag 1.

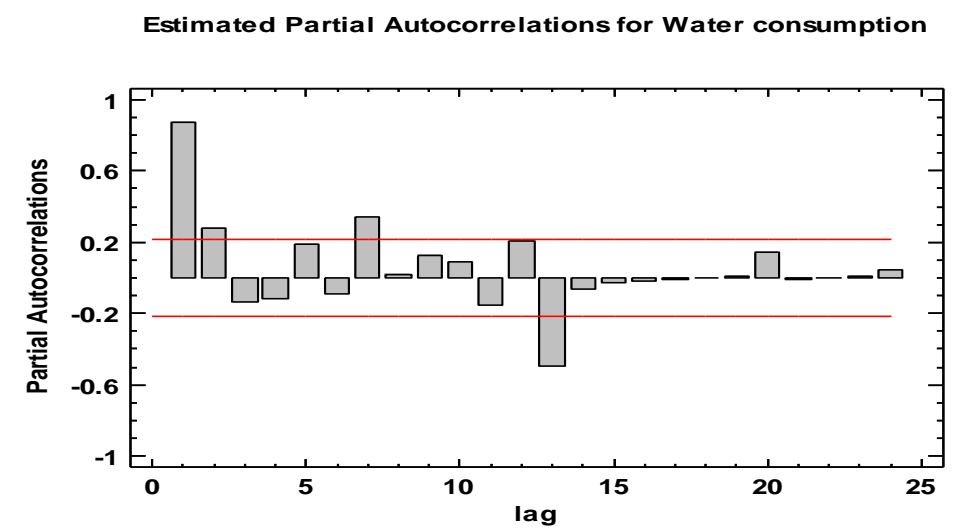

Figure 3. The PACF for the monthly water consumption data in Saudi Arabia between January 2010 and October 2016

Figure 3 shows that there is a spike in the PACF at lags 12, but nothing at seasonal lags in the ACF in Figure 2. This may be suggestive of a seasonal AR(1) term. In the non-seasonal lags, there are three significant spikes in the PACF, suggesting a possible AR(1) term. Note that from Figure 1 it can be seen that the water consumption data needs differencing seasonally, i.e. $\mathrm{D}=1, \mathrm{~d}=0$. The pattern in the ACF is not indicative of any simple model. Consequently, this initial analysis suggests that a possible model for this data is an $\operatorname{ARIMA}(1,0, q)(1,1, Q)[12]$.

\section{Estimated autocorrelations}

The estimated autocorrelations for the monthly water consumption data in Saudi Arabia are shown in Table 2. Table 2 depicts the estimated autocorrelations between values of water consumption at various lags. The lag $k=1,2, \ldots, 24$ autocorrelation coefficient measures the correlation between values of data at time $t$ and time $t-k$, where $t=1,2, \ldots, 82$. Also shown are $95.0 \%$ probability limits around 0 . The lower and upper limits of the $95 \%$ probabilities are shown in Figure 2; these limits are computed by $0 \mp z_{\alpha / 2} s e\left(r_{1}\right)$, where $z_{\alpha / 2}=1.96($ at $\alpha=5 \%)$ and $s e\left(r_{i}\right)$ is the standard error of the corresponding autocorrelation $r_{\mathrm{i}}$. If the probability limits at a particular lag do not contain the corresponding autocorrelation, there is a statistically significant correlation at that lag at the $95 \%$ confidence level.

\section{Fitting SARIMA model}

Choosing the best model will involve obtaining some important values in fitting like the root mean squared error (RMSE), the mean absolute error (MAE), the mean absolute percentage error (MAPE), the mean percentage error (MPE) and Akaike Information Criterion (AIC), which will be compared to their corresponding values when applying the following seasonal ARIMA models:

$$
\text { (A) } \operatorname{ARIMA}(1,0,1) \times(1,1,2) 12 \text {, }
$$




$$
\begin{aligned}
& \text { (B) } \operatorname{ARIMA}(1,1,0) \times(1,1,2) 12, \\
& \text { (C) } \operatorname{ARIMA}(2,1,0) \times(1,1,2) 12, \\
& \text { (D) } \operatorname{ARIMA}(0,1,2) \times(1,1,2) 12, \\
& \text { (E) } \operatorname{ARIMA}(1,1,1) \times(1,1,2) 12 .
\end{aligned}
$$

Table 2. The estimated autocorrelations between values of data at various lags

\begin{tabular}{c|c|c|c|c}
\hline Lag & Autocorrelation $\left(r_{i}\right)$ & Stnd. error (se) & $\begin{array}{c}\text { Lower 95.0\% } \\
\text { Prob. limit }\end{array}$ & $\begin{array}{c}\text { Upper 95.0\% } \\
\text { Prob. limit }\end{array}$ \\
\hline 1 & 0.874044 & 0.110432 & -0.216442 & 0.216442 \\
2 & 0.830243 & 0.175579 & -0.34413 & 0.34413 \\
3 & 0.73833 & 0.218267 & -0.427796 & 0.427796 \\
4 & 0.653835 & 0.246853 & -0.483823 & 0.483823 \\
5 & 0.618248 & 0.267139 & -0.523583 & 0.523583 \\
6 & 0.539642 & 0.284052 & -0.556734 & 0.556734 \\
7 & 0.572324 & 0.296291 & -0.580722 & 0.580722 \\
8 & 0.551189 & 0.30948 & -0.60657 & 0.60657 \\
9 & 0.584533 & 0.321228 & -0.629597 & 0.629597 \\
10 & 0.61312 & 0.333948 & -0.654527 & 0.654527 \\
11 & 0.584835 & 0.347405 & -0.680902 & 0.680902 \\
12 & 0.63271 & 0.359211 & -0.704041 & 0.704041 \\
13 & 0.515042 & 0.372554 & -0.730193 & 0.730193 \\
14 & 0.468674 & 0.381138 & -0.747018 & 0.747018 \\
15 & 0.377864 & 0.388103 & -0.760669 & 0.760669 \\
16 & 0.301906 & 0.392563 & -0.769412 & 0.769412 \\
17 & 0.270082 & 0.395385 & -0.774942 & 0.774942 \\
18 & 0.198321 & 0.397628 & -0.779339 & 0.779339 \\
19 & 0.228487 & 0.398833 & -0.781699 & 0.781699 \\
20 & 0.218865 & 0.400426 & -0.784822 & 0.784822 \\
21 & 0.251958 & 0.401882 & -0.787676 & 0.787676 \\
22 & 0.277167 & 0.403804 & -0.791443 & 0.791443 \\
23 & 0.250263 & 0.406117 & -0.795977 & 0.795977 \\
24 & 0.29124 & 0.407994 & -0.799655 & 0.799655 \\
\hline
\end{tabular}

Table 3 represents the comparison results of fitting different models. The model with the lowest value of the Akaike Information Criterion (AIC) is model (A). In addition, the model ARIMA $(1,0,1) \times(1,1,2) 12$ has the lowest values in RMSE, MPE and AIC. Therefore, the model ARIMA $(1,0,1) \times(1,1,2) 12$ is the best selected model. Table 4 also summarizes the performance of the currently selected model in fitting the historical data. The parameter estimates of the best model are also shown in Table 4. 
Table 3. A comparison fitting models

\begin{tabular}{c|c|c|c|c|c}
\hline Model & RMSE & MAE & MAPE & MPE & AIC \\
\hline (A) & $2.87793 \mathrm{E} 6$ & $2.20079 \mathrm{E} 6$ & 0.954075 & -0.0270854 & 29.8671 \\
(B) & $2.91554 \mathrm{E} 6$ & $2.26702 \mathrm{E} 6$ & 0.978276 & 0.0428601 & 29.8687 \\
(C) & $2.88255 \mathrm{E} 6$ & $2.1878 \mathrm{E} 6$ & 0.9434 & 0.0419334 & 29.8703 \\
(D) & $2.89092 \mathrm{E} 6$ & $2.22338 \mathrm{E} 6$ & 0.959992 & 0.0608748 & 29.8761 \\
(E) & $2.8966 \mathrm{E} 6$ & $2.20382 \mathrm{E} 6$ & 0.952618 & 0.0371123 & 29.8800 \\
\hline
\end{tabular}

Table 4. The parameter estimates of ARIMA $(1,0,1) \times(1,1,2) 12$

\begin{tabular}{c|c|c|c|c}
\hline Parameter & Estimate & Stnd. error & T & P-value \\
\hline$\phi_{1}$ & 1.00174 & 0.001590 & 629.884 & 0.000000 \\
$\theta_{1}$ & 0.470192 & 0.108953 & 4.31553 & 0.000056 \\
$\Phi_{1}$ & -1.24844 & 0.106268 & -11.748 & 0.000000 \\
$\Theta_{1}$ & -0.459525 & 0.128718 & -3.57001 & 0.000678 \\
$\Theta_{2}$ & 0.897565 & 0.115493 & 7.77157 & 0.000000 \\
\hline
\end{tabular}

The equation of the $\operatorname{ARIMA}(1,0,1) \times(1,1,2) 12$ is given as below(Eqs. 5-7). If

$$
\left(1-\varphi_{1} \beta\right)\left(1-\Phi_{1} \beta^{12}\right)\left(1-\beta^{12}\right) W C_{t}=\left(1-\theta_{1} \beta\right)\left(1-\Theta_{1} \beta^{12}-\Theta_{2} \beta^{24}\right) e_{t}
$$

then

$$
\begin{aligned}
W C_{t}= & \varphi_{1} W C_{t-1}+\left(\Phi_{1}+1\right) W C_{t-12}-\varphi_{1}\left(\Phi_{1}+1\right) W C_{t-13}-\Phi_{1} W C_{t-24}+\varphi_{1} \Phi_{1} W C_{t-25}, \text { (Eq.6) } \\
& +\left(\theta_{1}+\Theta_{1}\right) e_{t-12}-\left(\Theta_{2}-\theta_{1} \Theta_{1}\right) e_{t-24}+\theta_{1} \Theta_{2} e_{t-36}+e_{t} \\
W C_{t}= & 1.00174 W C_{t-1}-0.24844 W C_{t-12}+0.31062 W C_{t-13}+1.24844 W C_{t-24} . \quad \text { (Eq.7) } \\
& -1.25061 W C_{t-25}+0.01067 e_{t-12}-1.11363 e_{t-24}+0.21606 e_{t-36}+e_{t}
\end{aligned}
$$

\section{Forecasting}

We used Equation 7 to forecast data from November 2016 to July 2017; the forecasting results are given in Table 5.

Table 5. Forecasting data from November 2016 to July 2017

\begin{tabular}{c|c|c}
\hline Period & Original $\left(\mathbf{m}^{\mathbf{3}}\right)$ & Forecast $\left(\mathbf{m}^{\mathbf{3}}\right)$ \\
\hline $11 / 16$ & 261071635.00 & $2.63039 \mathrm{E} 8$ \\
$12 / 16$ & 262529383.00 & $2.67532 \mathrm{E} 8$ \\
$1 / 17$ & 264786946.00 & $2.62222 \mathrm{E} 8$ \\
$2 / 17$ & 231301561.00 & $2.39871 \mathrm{E} 8$ \\
$3 / 17$ & 268909016.00 & $2.64531 \mathrm{E} 8$ \\
$4 / 17$ & 269628773.00 & $2.65293 \mathrm{E} 8$ \\
$5 / 17$ & 285437797.00 & $2.79714 \mathrm{E} 8$ \\
$6 / 17$ & 269723694.00 & $2.78574 \mathrm{E} 8$ \\
$7 / 17$ & 273197966.00 & $2.90016 \mathrm{E} 8$ \\
\hline
\end{tabular}


The root mean square error between original data and the forecasted data is calculated, that is RMSE $=7751794.934$.

From Figure 4 it can be seen that there is a good agreement between the original and forecasted data. Therefore, we conclude that the fitted model, $\operatorname{ARIMA}(1,0,1) \times$ $(1,1,2) 12$, is appropriate for forecasting.

Water Consumption

$\operatorname{ARIMA}(1,0,1) \times(1,1,2) 12$

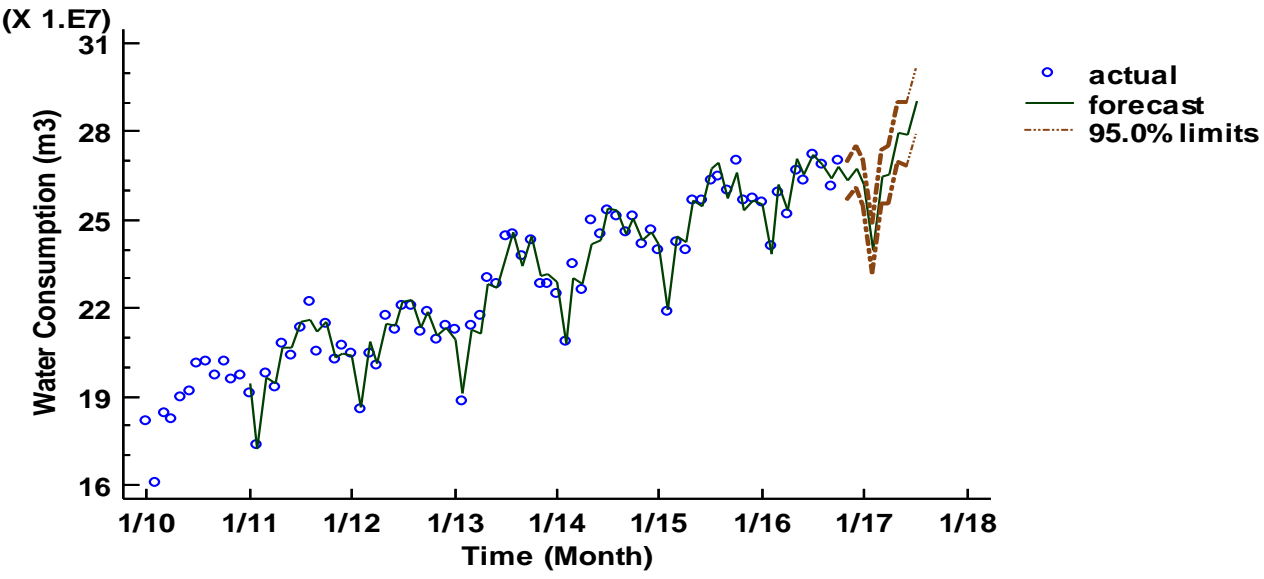

Figure 4. Forecast values based on the SARIMA model (green) and the original values (blue)

\section{Conclusions}

This research aimed is to understand current household water consumption by analyzing the current behaviour and water consumption patterns in Saudi Arabia, and to build a model that will encourage sustainable consumption and conservation of water resources. In this paper, we present a different time series model for fitting the monthly household water consumption data in Saudi Arabia between January 2010 and October 2016. Based on the data analyses and comparisons of five SARIMA models, the result indicated that the suitable and effective model for representing the household water consumption data of the time series is the multiplied seasonal model $\operatorname{ARIMA}(1,0,1) \times$ $(1,1,2) 12$. This model is used then to forecast the monthly water consumption in Saudi Arabia from the period November 2016 to July 2017. The forecasted values show the harmony with its counterparts in the original series values. This result provides a future image of the reality of monthly water demand in Saudi Arabia. Therefore, the officials and decision-makers can adopt the results of this study to face monthly water demand in Saudi Arabia (water scarcity). In particular, the identified multiplicative SARIMA model can be employed by the Ministry of Environment, Water and Agriculture in Saudi Arabia to ensure sustainable water resources management in the basin.

For future study, new modern statistics such as functional time series or fractional time series may be used in analyzing the water consumption data in Saudi Arabia, and the results can be then compared to the SARIMA model and its findings.

Acknowledgements. The authors extend their appreciation to the Deanship of Scientific Research at King Khalid University for funding this work through General Research Project under grant number (G.R.P-58-38). 


\section{REFERENCES}

[1] Abushammala. M. F. M., Bawazir. A. K. (2017): Domestic water demand forecasting for Makkah, Saudi Arabia. - European Water 58: 481-487.

[2] Agthe, D. E., Billings, R. B. (1980): Dynamic models of residential water demand. Water Resources Research 16(3): 476-480.

[3] Al-Ibrahim, A. A. (1990): Water use in Saudi Arabia: problems and policy implications. - Journal of Water Resources Planning and Management 116: 375-388.

[4] Arbués-Gracia, F., García-Valiñas, M. A., Martínez-Espiñeira, R. (2003): Estimation of residential water demand: a state of the art review. - Journal of Socio-Economics 32(1): 81-102.

[5] Box, G. E. P., Jenkins, G. M. (1970): Time Series Analysis, Forecasting and Control, 3rd ed. - Prentice Hall, Englewood Cliffs, NJ.

[6] Chicoine, D. L., Deller, S. C., Ramamurthy, G. (1986): Water demand estimation under block rate pricing: a simultaneous equation approach. - Water Resources Research 22(6): 859-863.

[7] Cornillon, P., Imam, W., Matzner, E. (2008): Forecasting time series using principal component analysis with respect to instrumental variables. - Computational Statistics and Data Analysis 52: 1269-1280.

[8] Dalhuisen, J. M., Florax, R., De Groot, H., Nijkamp, P. (2003): Price and income elasticities of residential water demand: a meta-analysis. - Land Economics 79(2): 292308.

[9] Davis, W. Y. (2005): Water demand forecast methodology for California water planning area work plan and model review. - Research Report, California Bay-Delta Authority, CA, USA 19: 137-148.

[10] Dickey, D. A., Fuller, W. A. (1979): Distribution of the estimators for autoregressive time series with unit root. - Journal of the American Statistical Association USA 74: 427-431.

[11] Foster, H. S. J., Beattie, B. R. (1979): Urban residential demand for water in the United States. - Land Economics 55(1): 43-58.

[12] Gottlieb, M. (1963): Urban domestic demand or water in the United States. - Land Economics 39(2): 204-210.

[13] Hamilton, J. D. (1994): Time Series Analysis. - Princeton University Press, United State of America, Princeton, NJ.

[14] Hansen, L. G. (1996): Water and energy price impacts on residential water demand in Copenhagen. - Land Economics 72(1): 66-79.

[15] Höglund, L. (1999): Household demand for water in Sweden, with implications of a potential tax on water use. - Water Resources Research 35(12): 3853-3863.

[16] Hongyan, L., Yuabiao, Z., Zhifeng, C., Zexin, M. (2017): Evaluation and prediction of regional water resources carrying capacity: a case study of Shandong Province. Environment and Natural Resources Research 7(1): 21-33.

[17] Howe, C. W., Lina weaver, F. P. (1967): The impact of price on residential water demand and its relationship to system design and price structure. - Water Resources Research 3(1): 13-32.

[18] Kambale, J. B., Singh, D. K., Sarangi, A. (2016): impact of climate change on groundwater recharge in a semi-arid region of Northern India. - Applied Ecology and Environmental Research 15(1): 335-362.

[19] Kulshreshtha, S. N. (1996): Residential water demand in Saskatchewan communities: role played by block pricing system in water conservation. - Canadian Water Resources Journal 21(2): 139-155.

[20] Martínez-Espiñeira, R. (2002): Residential water demand in the northwest of Spain. Environmental and Resource Economics 21(2): 161-187.

[21] Ministry of Environment, Water and Agriculture, Saudi Arabia. http://app.mowe.gov.sa/IPS/IPS/Query/InforKSA.aspx?\&Min=1\&UserId=. 
[22] Muhamad, S., Nurul, H., Mohd, T., Vigneswary, P., Mohd, N., Razak, Z., Suffian, M. D., Idham, K. (2018): Improving the performance of ANN-ARIMA models for predicting water quality in the offshore area of Kuala Terengganu, Malaysia. - Journal of Sustainability Science and Management 13(1): 27-37.

[23] Nauges, C., A. Thomas. (2000): Privately-operated water utilities, municipal price negotiation, and estimation of residential water demand: the case of France. - Land Economics 76(1): 68-85.

[24] Nieswiadomy, M. L., Molina, D. J. (1989): Comparing residential water demand estimates under decreasing and increasing block rates using household data. - Land Economics 65(3): 280-289.

[25] Rita, S., Yony, H., Rubiyanto, Fakhri, A. M., Madzlan, A. (2013): Multiple linear regression (MLR) modeling of wastewater in urban region of southern Malaysia. Journal of Sustainability Science and Management 8(1): 93-102.

[26] Samsuri, A., Marzuki, I., Si, Y. F. (2017): Multiple linear regression (MLR) models for long term Pm10 concentration forecasting during different monsoon seasons. - Journal of Sustainability Science and Management 12(1): 60-69.

[27] Wei, W. W. S. (2006): Time Series Analysis: Univariate and Multivariate Methods, 2nd Edition. - Addison-Wesley, Boston.

\section{APPENDIX}

Monthly water consumption data in Saudi Arabia between January 2010 and July 2017 (Ministry of Environment, Water and Agriculture, Saudi Arabia)

\begin{tabular}{c|c|c|c|c|c}
\hline Year & Month & Water consumption $\left(\mathbf{m}^{\mathbf{3}}\right)$ & Year & Month & Water consumption $\left(\mathbf{m}^{\mathbf{3}}\right)$ \\
\hline \multirow{6}{*}{2010} & 1 & 181939098 & & 1 & 224952954 \\
& 2 & 160540706 & & 2 & 208397220 \\
& 3 & 184361371 & & 3 & 234749774 \\
& 4 & 182276377 & & 4 & 225968489 \\
& 5 & 190071038 & & 5 & 249799599 \\
& 6 & 191941944 & \multirow{2}{*}{2014} & 6 & 245316101 \\
& 7 & 201353276 & & 7 & 253530687 \\
& 8 & 201911967 & & 8 & 250959716 \\
& 9 & 197210257 & & 9 & 245723978 \\
& 10 & 201739765 & & 10 & 250966000 \\
& 11 & 195916912 & & 11 & 241421651 \\
& 12 & 197488790 & & 12 & 246410894 \\
\hline \multirow{5}{*}{2011} & 1 & 191445402 & & 1 & 239995376 \\
& 2 & 173252570 & & 2 & 218625646 \\
& 3 & 197589877 & & 3 & 242120060 \\
& 4 & 193327291 & & 4 & 239764261 \\
& 5 & 208026292 & & 5 & 256585620 \\
& 6 & 204244441 & 2015 & 6 & 256445988 \\
& 7 & 213421578 & & 7 & 263626853 \\
& 8 & 222289987 & & 8 & 265025393 \\
& 9 & 205258673 & & 9 & 260071576 \\
& 10 & 214452752 & & 10 & 269842591 \\
& 11 & 202692522 & & 11 & 256272921
\end{tabular}




\begin{tabular}{l|c|c|c|c|c} 
& 12 & 207495739 & & 12 & 257284729 \\
\hline \multirow{5}{*}{2012} & 1 & 204710434 & & 1 & 255794090 \\
& 2 & 185681806 & & 2 & 240752352 \\
& 3 & 204947388 & & 3 & 259296870 \\
& 4 & 200254874 & & 4 & 251720038 \\
& 5 & 217412155 & & 5 & 266836225 \\
& 6 & 212579186 & \multirow{2}{*}{2016} & 6 & 263387877 \\
& 7 & 220756924 & & 7 & 272165315 \\
& 8 & 220619235 & & 8 & 268817999 \\
& 9 & 212082770 & & 9 & 261302224 \\
& 10 & 218817360 & & 10 & 270277919 \\
& 11 & 209670441 & & 11 & 261071635 \\
& 12 & 213826019 & & 12 & 262529383 \\
\hline \multirow{5}{*}{2013} & 1 & 212915242 & & 1 & 264786946 \\
& 2 & 188238373 & & 2 & 231301561 \\
& 3 & 213767580 & & 3 & 268909016 \\
& 4 & 217117937 & & 4 & 269628773 \\
& 5 & 230191686 & & 5 & 285437797 \\
& 6 & 228494648 & \multirow{2}{*}{2017} & 6 & 269723694 \\
& 7 & 244452775 & & 7 & \\
& 8 & 244873159 & & & \\
& 9 & 237947752 & & & \\
& 10 & 242969366 & & & \\
& 11 & 228361039 & & & \\
& 12 & 228428423 & & & \\
\hline
\end{tabular}

